doi: $10.2306 /$ scienceasia1513-1874.2012.38.244

\title{
Effect of cryopreservation on seed germination and protocorm development of Vanda tricolor
}

\author{
Nipawan Jitsopakul ${ }^{\mathrm{a}}$, Kanchit Thammasiri ${ }^{\mathrm{b}, *}$, Tomohisa Yukawac ${ }^{\mathrm{c}}$, Keiko Ishikawa \\ a Department of Agro-Industry, Faculty of Agriculture and Technology, \\ Rajamangala University of Technology Isan, Surin Campus, Surin 32000, Thailand \\ b Department of Plant Science, Faculty of Science, Mahidol University, Bangkok 10400, Thailand \\ c Tsukuba Botanical Garden, National Science Museum, Tsukuba 305-0005, Japan \\ d Department of Research and Development, Japan Horticultural Production and Research Institute, \\ Chiba 270-2221, Japan
}

*Corresponding author, e-mail: kanchitthammasiri@gmail.com

\begin{abstract}
Germination and subsequent development was assessed after seeds of Vanda tricolor were stored in liquid nitrogen. Mature seeds, harvested 7 months after self-pollination, were directly plunged into liquid nitrogen. Germination of cryopreserved seeds on solid New Dogashima (ND) medium supplemented with $1 \mathrm{mg} / \mathrm{l}$ 6-benzyladenine, $0.5 \mathrm{mg} / \mathrm{l}$ 1-naphthaleneacetic acid and $2 \%$ sucrose was faster than non-cryopreserved seeds (28 days versus 60 days after sowing). Immature seeds, harvested 6 months after self-pollination, were treated with or without loading solution (LS) of $2 \mathrm{M}$ glycerol and $0.4 \mathrm{M}$ sucrose in liquid ND medium, $\mathrm{pH} 5.4$ at $25^{\circ} \mathrm{C}$ for $15 \mathrm{~min}$ and dehydrated with PVS2 solution for 0-210 min on ice and then cryopreserved by vitrification. The results showed that the germination percentage of cryopreserved seeds treated with LS was higher than without LS. After 90 days of sowing, the highest germination percentage of cryopreserved seeds was $13.6 \%$ which was higher than non-cryopreserved seeds (10.5\%) when seeds were treated with LS for 15 min and then dehydrated with PVS2 solution for $180 \mathrm{~min}$. After 150 days of sowing, protocorms of non-cryopreserved and cryopreserved seeds were able to form new protocorms (budding protocorms) and developed into shoots after 180 days of sowing. There were no significant differences between growth and development of protocorms derived from noncryopreserved and cryopreserved seeds.
\end{abstract}

KEYWORDS: liquid nitrogen, immature seeds, mature seeds, vitrification, ND medium

\section{INTRODUCTION}

Orchid seeds are conventional in the sense that storing them under room or cold temperature reduce their viability over time ${ }^{1}$. To avoid this, cryopreservation of seeds is a feasible way of preserving their genetic diversity. Cryopreservation using liquid nitrogen $\left(-196^{\circ} \mathrm{C}\right)$ is an important technique for longterm preservation without genetic alteration because extremely low temperature stops all biological activities $^{2}$. Orchid seeds are very small, tolerant to freezing, and suitable for long-term preservation. It has been reported that seeds of Bratonia ${ }^{3}$, immature seeds of Bletilla striata ${ }^{4}$, and seeds of rare tropical orchids ${ }^{1}$ could be frozen by directly plunging into liquid nitrogen.

Vitrification methods involve treatment of samples with a highly concentrated cryoprotective solution, such as plant vitrification solution formula 2 (PVS2), to induce dehydration of the cells which reduces the chances of intracellular ice formation during freezing in liquid nitrogen ${ }^{2}$. This method has been applied to many orchid species, such as zygotic embryos of $B$. striata $^{5}$, cell suspension culture of Doritaenopsis $^{6}$, seeds of Doritis pulcherrima ${ }^{7}$ and V. coerulea $^{8}$, and immature seeds of B. striata $^{4}$ and Ponerochis graminifolia var. suzukiana ${ }^{9}$.

The most important requirement for success after cryopreservation is similar to that of germination and development of non-cryopreserved seeds. Under natural condition, orchid seeds require a symbiosis with fungi for growth and development ${ }^{10,11}$. However, orchid seeds can germinate and develop in vitro. V. tricolor is an outstanding vandaceous orchid found on rocks or trees. It is native to East Java, Indonesia, and has large flowers with deep-coloured markings and fragrance. The aim of this work was to study the effect of $V$. tricolor seed stored in liquid nitrogen on germination and protocorm development in vitro. 


\section{MATERIALS AND METHODS}

\section{Plant material}

The capsules of $V$. tricolor were harvested 6 months (immature seeds) or 7 months (mature seeds) after self-pollination from Tsukuba Botanical Garden, Tsukuba, Japan. The capsules were washed with running tap water for $3 \mathrm{~min}$. Then, the capsules were brought inside a laminar air- flow cabinet, soaked in 95\% ethanol for $1 \mathrm{~min}$ and then flamed with a lamp. The seeds were removed from the capsules and used for this study.

\section{CRYOPRESERVATION}

\section{Directly plunging into liquid nitrogen}

Seeds from $V$. tricolor capsules harvested 6 and 7 months after self-pollination were transferred into $2 \mathrm{ml}$ cryotubes, and then directly plunging into liquid nitrogen. After 1 day, the cryotubes were rapidly warmed in a water bath at $40{ }^{\circ} \mathrm{C}$ for $1 \mathrm{~min}$. Noncryopreserved and cryopreserved seeds were sown on solidified New Dogashima (ND) medium ${ }^{12}$ supplemented with $1 \mathrm{mg} / \mathrm{l}$ 6-benzyladenine (BA) and $0.5 \mathrm{mg} / 1$ 1-naphthaleneacetic acid (NAA), 2\% sucrose. The $\mathrm{pH}$ of the medium was adjusted to 5.4 with $1 \mathrm{~N} \mathrm{NaOH}$ or $1 \mathrm{~N} \mathrm{HCl}$ before the addition of $0.2 \%$ gellan gum ${ }^{5}$. The cultures were maintained at $25^{\circ} \mathrm{C}$ under dark conditions for 3 weeks, and then transferred under a light intensity of $62 \mu \mathrm{mol} \mathrm{m} \mathrm{m}^{-2} \mathrm{~s}^{-1}$ with a $16 \mathrm{~h}$ light $/ 8 \mathrm{~h}$ dark photoperiod at $25^{\circ} \mathrm{C}$. In this experiment, $0.05 \mathrm{~g}$ of seeds (300-400 seeds) was tested for each of five replicates.

\section{Vitrification method}

Seeds from $V$. tricolor capsules harvested 6 months after self-pollination were transferred into $2 \mathrm{ml}$ cryotube, and then treated with or without loading solution (LS) of $2 \mathrm{M}$ glycerol and $0.4 \mathrm{M}$ sucrose in liquid $\mathrm{ND}$ medium, pH 5.4 at $25^{\circ} \mathrm{C}$ for $15 \mathrm{~min}$. Following removal of LS, the seeds were dehydrated with PVS2 solution $^{2}$. The PVS2 solution consisted of $30 \%(\mathrm{w} / \mathrm{v})$ glycerol, $15 \%(\mathrm{w} / \mathrm{v})$ ethylene glycol and $15 \%(\mathrm{w} / \mathrm{v})$ DMSO in liquid ND medium with $0.4 \mathrm{M}$ sucrose and $\mathrm{pH} 5.4$ on ice for 0-210 min. After dehydration, the seeds were suspended into $1 \mathrm{ml}$ of PVS2 solution in $2 \mathrm{ml}$ cryotube and then directly plunged into liquid nitrogen. After 1 day, the cryotubes were rapidly warmed in a water bath at $40^{\circ} \mathrm{C}$ for $1 \mathrm{~min}$. PVS2 solution was removed from cryotube and then $1 \mathrm{ml}$ of liquid ND medium supplemented with $1.2 \mathrm{M}$ sucrose were added to each tube and held for $20 \mathrm{~min}$. Cryopreserved seeds were sown on solidified ND medium supplemented with $2 \%$ sucrose, $0.2 \%$ gellan gum and $\mathrm{pH}$ 5.4. Cultures were maintained under a light intensity of $62 \mu \mathrm{mol} \mathrm{m}{ }^{-2} \mathrm{~s}^{-1}$ with a $16 \mathrm{~h}$ light $/ 8 \mathrm{~h}$ dark photoperiod at $25^{\circ} \mathrm{C}^{5}$.

As a control (non-cryopreserved), seeds were treated with or without LS, and then dehydrated with PVS2 solution in the same way as described above. PVS2 solution was removed and then $1 \mathrm{ml}$ of liquid ND medium supplemented with $1.2 \mathrm{M}$ sucrose was added for $20 \mathrm{~min}$. Seeds were sown on solidified ND medium in the same way as described above.

In this experiment, $0.05 \mathrm{~g}$ of seeds (300-400 seeds) was tested for each of five replicates.

\section{Water content}

About $0.3 \mathrm{~g}$ of seeds was dried for 2 days with a dry incubator at $70{ }^{\circ} \mathrm{C}$. The percentage of water content was calculated on the basis of the fresh weight.

\section{Germination percentage}

In the directly plunged into liquid nitrogen method, germination percentage was calculated on the basis of protocorms or seedlings developed from noncryopreserved and cryopreserved seeds after 120 days of sowing. In the vitrification method, germination percentage was calculated on the basis of protocorms developed from non-cryopreserved and cryopreserved seeds after 90 days of sowing.

\section{Development of protocorms}

After 120 days of sowing, 100 protocorms per treatment (about $0.5 \mathrm{~mm}$ in diameter) developed from non-cryopreserved and cryopreserved seeds after cryopreservation by vitrification method were collected, and transferred on fresh solidified ND medium supplemented with $1 \mathrm{mg} / \mathrm{l} \mathrm{BA}$ and $0.5 \mathrm{mg} / \mathrm{l} \mathrm{NAA,} 2 \%$ sucrose, $\mathrm{pH}$ 5.4. Cultures were maintained under a light intensity of $62 \mu \mathrm{mol} \mathrm{m}{ }^{-2} \mathrm{~s}^{-1}$ with a $16 \mathrm{~h}$ light $/ 8 \mathrm{~h}$ dark photoperiod at $25^{\circ} \mathrm{C}^{5}$.

The size of protocorms was measured after 150 days of sowing and the number of new protocorms developed from one protocorm was counted after 180 days of sowing. The number of new protocorms was calculated from the total of protocorms that formed new protocorms. The germination of seeds and the development of protocorms were observed under the microscope.

After 180 days of sowing, 50 seedlings were transferred to fresh solidified ND medium without plant growth regulator (BA and NAA) for the study of morphology of plantlets developed from noncryopreserved and cryopreserved seeds. 
Table 1 Effect of seed age on water content, germination time and germination percentage of non-cryopreserved and cryopreserved seeds of $V$. tricolor by directly plunging into liquid nitrogen.

\begin{tabular}{|c|c|c|c|c|c|}
\hline \multirow{2}{*}{$\begin{array}{l}\text { Age } \\
\text { of pod } \\
\text { (months) }\end{array}$} & \multirow{2}{*}{$\begin{array}{c}\text { Water } \\
\text { content } \\
(\%)\end{array}$} & \multicolumn{2}{|c|}{$\begin{array}{c}\text { Germination time } \\
\text { (days) }\end{array}$} & \multicolumn{2}{|c|}{$\begin{array}{c}\text { Germination } \\
(\%)\end{array}$} \\
\hline & & $\begin{array}{l}\text { non-cryo- } \\
\text { preserved } \\
\text { seeds }\end{array}$ & $\begin{array}{l}\text { cryopre- } \\
\text { served } \\
\text { seeds }\end{array}$ & $\begin{array}{l}\text { non-cryo- } \\
\text { preserved } \\
\text { seeds }\end{array}$ & $\begin{array}{l}\text { cryopre- } \\
\text { served } \\
\text { seeds }\end{array}$ \\
\hline 6 & $45^{\mathrm{b}}$ & $35^{\mathrm{a}}$ & $30^{\mathrm{b}}$ & $26.4 \pm 0.5^{\mathrm{a}}$ & $10.0 \pm 1.1^{\mathrm{a}}$ \\
\hline 7 & $40^{\mathrm{a}}$ & $60^{\mathrm{b}}$ & $28^{\mathrm{a}}$ & $11.3 \pm 0.5^{\mathrm{b}}$ & $1.0 \pm 0.04^{b}$ \\
\hline
\end{tabular}

Similar letters within columns mean no significant difference at $P \leqslant 0.05$ by LSD test.

\section{Statistical analysis}

Germination, size of protocorms, percentage of protocorms formed new protocorms and the number of new protocorms developed from non-cryopreserved and cryopreserved seeds was subjected to ANOVA and the means were compared using the least significant difference (LSD) test.

\section{RESULTS AND DISCUSSION}

\section{Characteristic of $\boldsymbol{V}$. tricolor capsules}

The size of $V$. tricolor capsules harvested 6 and 7 months after self-pollination was $2 \times 11 \mathrm{~cm}$ and $2.2 \times 10.5 \mathrm{~cm}$ in length and the fresh weight of capsules was $16.06 \mathrm{~g}$ and $13.09 \mathrm{~g}$, respectively. Seeds from the capsules harvested 6 months after selfpollination were yellow (immature seeds) and the seeds from capsules harvested 7 months after selfpollination were brown (mature seeds). The water content of seeds from capsules harvested 6 and 7 months after self-pollination measured was $45 \%$ and $40 \%$, respectively (Table 1 ). There were significant differences between the water content of seeds from capsules harvested 6 and 7 months. The water content of seeds decreased with increasing time after selfpollination ${ }^{4}$.

\section{Cryopreservation of seeds by directly plunging into liquid nitrogen}

Germination of cryopreserved immature seeds occurred 30 days after sowing which was faster than non-cryopreserved (35 days) (Table 1). The germination percentage of cryopreserved seeds was $10 \%$ which was lower than those of non-cryopreserved (26.4\%). Conversely, the germination of cryopreserved mature seeds occurred 28 days after sowing, earlier than that of non-cryopreserved seeds (60 days). The germination percentage of cryopreserved seeds was $1.0 \%$ which was lower than those of noncryopreserved seeds (11.3\%).

These results indicate that mature seeds may have a dormancy mechanism that could have induced the accumulation of inhibitory substances or increased the impermeability of the embryo ${ }^{13}$. The seeds treated with liquid nitrogen could have depleted food reserves $^{3}$, or storage in liquid nitrogen might result in partial breakdown of seed coat (testa).

Germination of mature seeds of $V$. tricolor occurred after the uptake of water after 15 days of sowing (Fig. 1a). At this point the testa ruptured 20 days after sowing (Fig. 1b). The protocorms emerged from the testa (Fig. 1c) and by 28 days of sowing developed a green colour (Fig. 1d).

The water content in seeds is an important factor of their successful freezing ${ }^{4}$. However, in this experiment, immature seeds contained more water and germinated easier than the mature seeds. The immature seeds were used for the vitrification experiment to investigate whether a higher germination percentage could be obtained after cryopreservation.

\section{Cryopreservation of immature seeds by vitrification method}

The effects of LS and exposure time to PVS2 solution on germination of immature seeds after cryopreservation by vitrification method are shown in Fig. 2 . The germination percentage (13.6\%) of cryopreserved seeds treated with LS was highest when exposed to PVS2 for the longest interval of $180 \mathrm{~min}$. However, in cryopreserved seeds without LS, the highest germination was $10.8 \%$ when dehydrated with PVS2 solution on ice for $90 \mathrm{~min}$. The LS treatment was very efficient in inducing dehydration and freezing tolerance in tissues $^{2,4,5}$. In this case, the optimal exposure time shifted from $60 \mathrm{~min}$ to $90 \mathrm{~min}$ with LS treatment. This may mean LS treatment enhanced the osmoprotection by PVS2. However, the highest germination of noncryopreserved seeds with and without LS treatment was $7.2 \%$ and $13.9 \%$, respectively. The germination of non-cryopreserved seeds decreased with LS treatment. The reason for this was not clear, but PVS2 solution and LS solution may stimulate germination of seeds.

The incubation time and temperature in PVS2 solution are critical to the germination of cryopreserved seeds because over-exposure to PVS2 can cause chemical toxicity. Dehydration time of explants at $0{ }^{\circ} \mathrm{C}$ reduces the toxicity of vitrification solution and increase exposure time to PVS2 solution ${ }^{14}$. Germination of non- cryopreserved and cryopreserved seeds decreased when the exposure time to PVS2 solution 

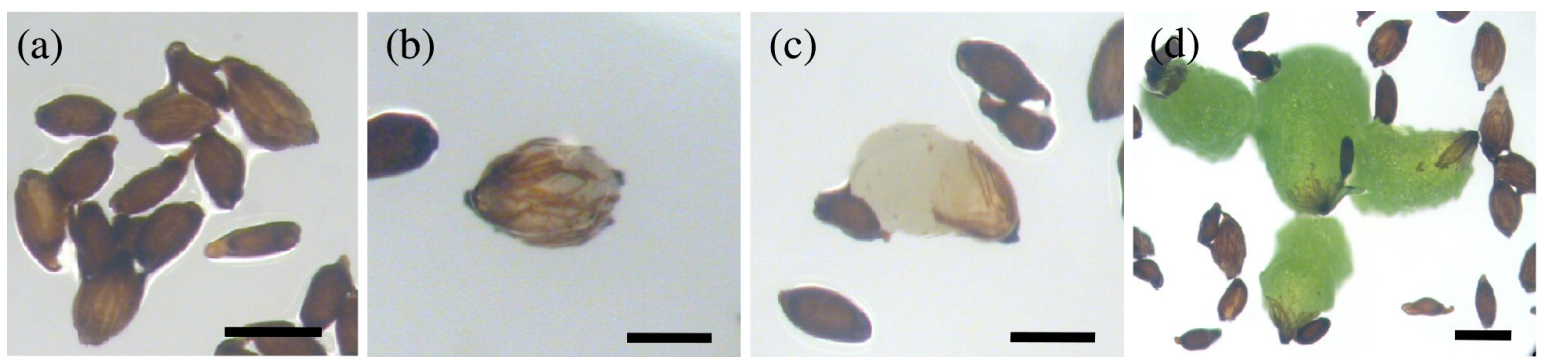

Fig. 1 Germination of cryopreserved mature seeds of $V$. tricolor after cryopreservation by directly plunging into liquid nitrogen. (a) 15 days, (b) 20 days, (c) and (d) 28 days of sowing. (Bar: (a)-(d) $=0.5 \mathrm{~mm}$ ).

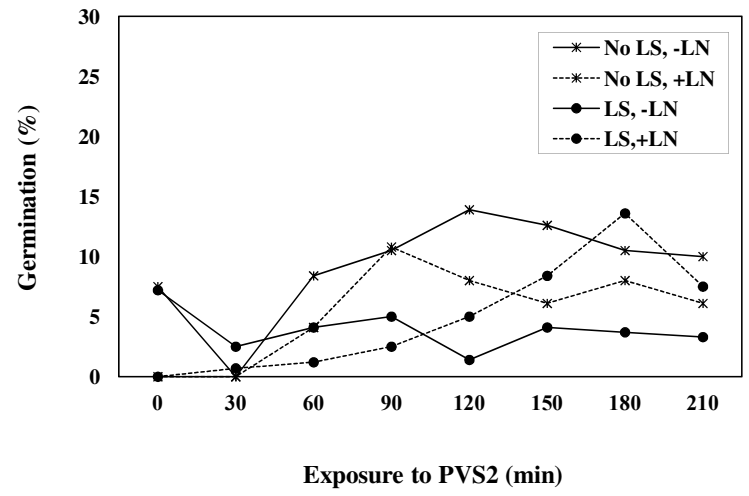

Fig. 2 Effect of seed (6 months old) cryopreservation by vitrification on the germination of non-cryopreserved seeds $(-\mathrm{LN})$ and cryopreserved seeds $(+\mathrm{LN})$ of $V$. tricolor after 90 days of sowing. Bars represent standard error.

increased. Increasing the expose time to PVS2 solution to $210 \mathrm{~min}$ resulted in a decline in cryopreserved seed germination to $7.5 \%$ and $6.1 \%$, respectively, when treated with or without LS, respectively.

Optimizing the time of exposure to PVS2 solution is the most important for immature seed germination after cryopreservation by vitrification (Fig. 2). Immature seeds were cooled in liquid nitrogen after dehydration with PVS2 solution for $0-210 \mathrm{~min}$ on ice without LS treatment. The highest germination of non-cryopreserved and cryopreserved seeds was $13.9 \%$ and $10.8 \%$ when exposure to PVS2 solution for $120 \mathrm{~min}$ and $90 \mathrm{~min}$, respectively. When seeds were treated with LS solution, the highest germination of non-cryopreserved seed was $7.2 \%$ without dehydration with PVS2 solution. Germination of cryopreserved seeds increased rapidly with increasing dehydration period and reached a maximum of about $13.6 \%$ when exposed to PVS2 solution for $180 \mathrm{~min}$ and then the germination decreased at $210 \mathrm{~min}$ due to the toxicity of PVS2 solution.

\section{Development of protocorms}

The growth and development of protocorms from non-cryopreserved and cryopreserved seeds is shown in Fig. 3. The size of protocorms increased with increasing time of sowing on solidified ND medium. There were no significant differences in size and number of protocorms developed from non-cryopreserved (Fig. 3a-c) and cryopreserved seeds (Fig. 3d-e). Protocorms began to elongate within 150 days of sowing and developed shoots within 180 days of sowing. Protocorms of $V$. tricolor have ability to form new protocorms (Fig. 4a-e).

After 180 days of sowing, formation of new protocorms and number of new protocorms per seed were observed. Protocorms of non-cryopreserved and cryopreserved seeds developed into normal seedlings (one shoot/seed) about 65-96\% and formed new protocorms about $4-35 \%$. The number of new protocorms increased with increasing time of sowing. A protocorm formed 2-14 new protocorms per seed. After 180 days of sowing, protocorms that formed one shoot were separated, and then transferred to fresh solidified ND medium without plant growth regulator (BA and NAA). There were no significant differences between the growth of seedlings derived from noncryopreserved and cryopreserved seeds.

\section{CONCLUSIONS}

This study showed that liquid nitrogen induced the germination of $V$. tricolor mature seeds. Liquid nitrogen did not affect growth and development of protocorms from cryopreserved seeds when compared with non-cryopreserved seeds. This method may be applicable to induce seed germination of other orchid species.

Acknowledgements: We thank Tsukuba Botanical Garden, Tsukuba, Japan for providing plant material and Japan Horticultural Production and Research Institute, Matsudo Chiba, Japan for training. 

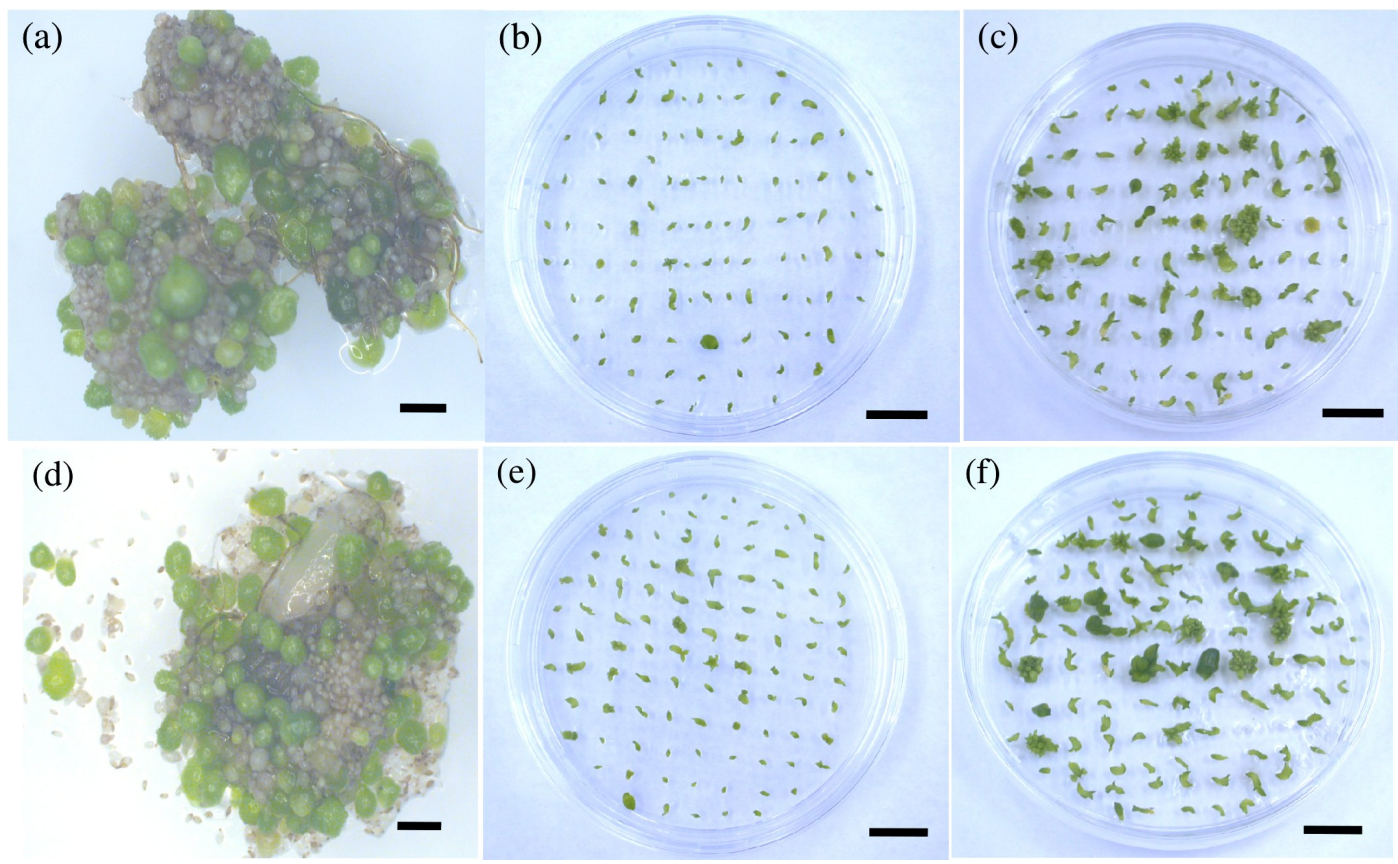

(e)

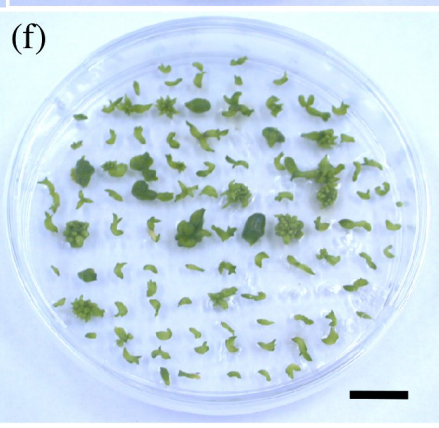

Fig. 3 Germination of non-cryopreserved and cryopreserved seeds (6 months old) and development of protocorms of $V$. tricolor after cryopreservation by vitrification. Immature seeds were treated with LS, then dehydrated with PVS2 solution for $120 \mathrm{~min}$. Germination of (a) non-cryopreserved seeds and (d) cryopreserved seeds after 120 days of sowing. Development of protocorms from (b), (c) non-cryopreserved seeds and (e), (f) cryopreserved seeds after 150 days and 180 days of sowing, respectively, (Bar: (a) and (d) $=1 \mathrm{~mm},(\mathrm{~b}),(\mathrm{c}),(\mathrm{e})$, and (f) $=1 \mathrm{~cm})$.

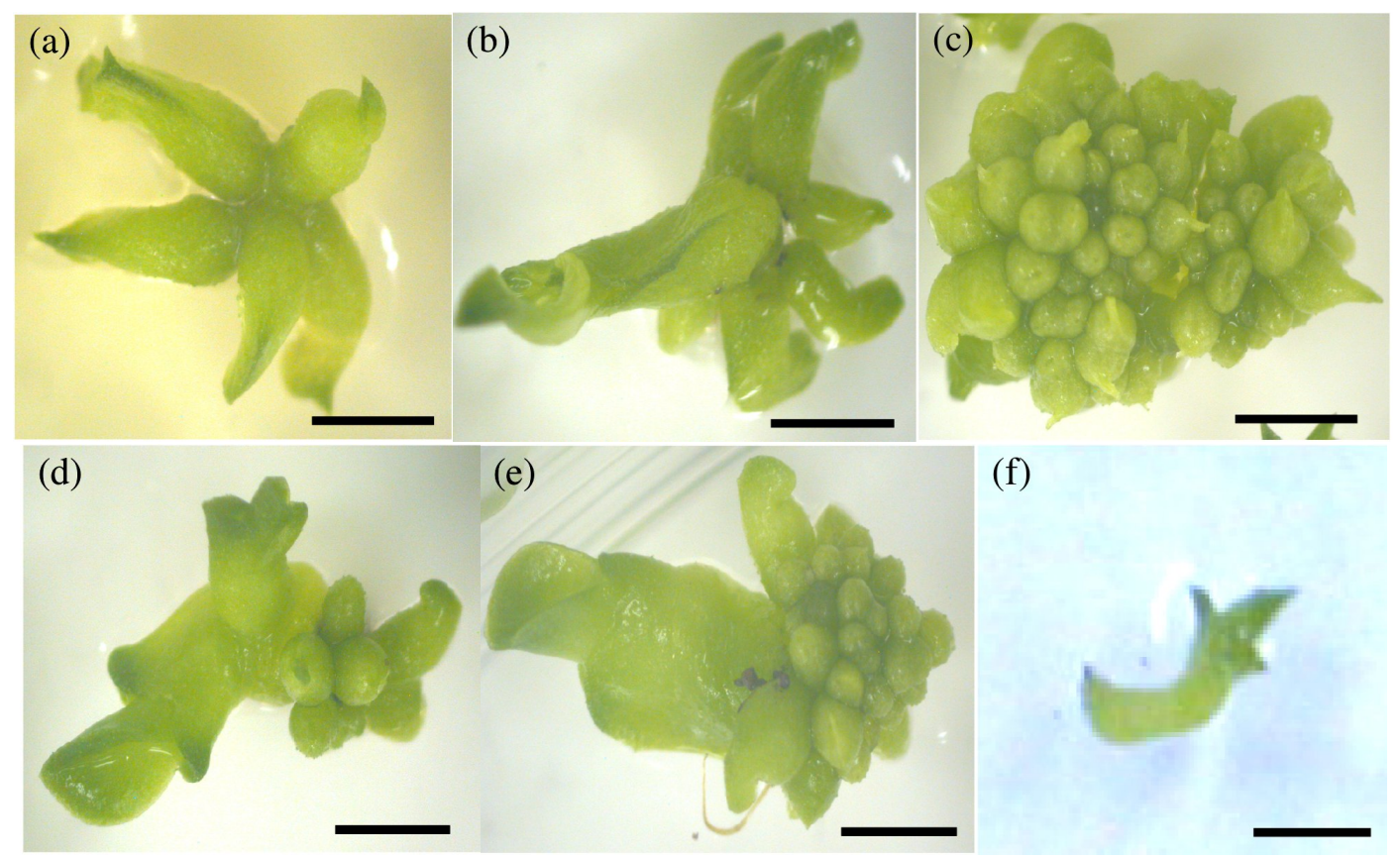

Fig. 4 Development of protocorms from cryopreserved seeds (6 months old) of V. tricolor. Immature seeds were treated with LS, then dehydrated with PVS2 solution for 90 min. (a)-(b) protocorms formed multiple shoots after 90 days of sowing, (c)-(e) protocorms formed new protocorms (budding protocorms) after 120 days of sowing, and (f) a protocorm developed into a shoot after 120 days of sowing under light condition $16 \mathrm{~h} / \mathrm{d}$. (Bar: (a)-(f) $=0.5 \mathrm{~cm}$ ). 


\section{REFERENCES}

1. Nikishina TV, Popov AS, Kolomeitseva GL, Golovkin BN (2001) Effect of cryopreservation on seed germination of rare tropical orchids. Russ J Plant Physiol 48, 810-5.

2. Sakai A, Koboyashi S, Oiyama I (1990) Cryopreservation of nucellar cells of navel orange (Citrus sinensis Osb. var. brasiliensis Tanaka) by vitrification. Plant Cell Rep 9, 30-3.

3. Popov AS, Popova EV, Nikishima TV, Kolomeytseva GL (2004) The development of juvenile plants of the hybrid orchid Bratonia after seed cryopreservation. CryoLetters 25, 205-12.

4. Hirano T, Godo T, Mii M, Ishikawa K (2005) Cryopreservation of immature seeds of Bletilla striata by vitrification. Plant Cell Rep 23, 534-9.

5. Ishikawa K, Harata K, Mii M, Sakai A, Yoshimatsu K, Shimonura K (1997) Cryopreservation of zygotic embryos of a Japanese terrestrial orchid (Bletilla striata) by vitrification. Plant Cell Rep 16, 745-57.

6. Tsukazaki H, Mii M, Tokuhara K, Ishikawa K (2000) Cryopreservation of Doritaenopsis suspension culture by vitrification. Plant Cell Rep 19, 1160-4.

7. Thammasiri K (2000) Cryopreservation of seeds of a Thai orchid (Doritis pulcherrima Lindl.) by vitrification. CryoLetters 21, 237-44.

8. Thammasiri K, Soamkul L (2007) Cryopreservation of Vanda coerulea Griff. ex Lindl. seeds by vitrification. Sci Asia 33, 223-7.

9. Hirano T, Ishikawa K, Mii M (2005) Cryopreservation of immature seeds of Ponerorchis graminifolia var. suzukiana by vitrification. CryoLetters 26, 139-46.

10. Chou LC, Chang DCN (2004) Asymbiotic and asymbiotic seed germination of Anoectochilus formosanus Hayata, Haemaria discolor var. dowsoniana and their F1 hybrids. Bot Bull Acad Sin 45, 143-7.

11. Shimura H, Koda Y (2005) Enhanced symbiotic seed germination of Cypripedium macranthos var. rebunense following inoculation after cold treatment. Physiol Plantarum 123, 281-7.

12. Tokuhara K, Mii M (1993) Micropropagation of Phalaenopsis and Doritaenopsis by culturing shoot tips of flower stalk buds. Plant Cell Rep 13, 7-11.

13. Miyoshi K, Mii M (1998) Stimulatory effects of sodium and calcium hypochlorite, pre-chilling and cytokinins on the germination of Cypripedium macranthos seed in vitro. Physiol Plantarum 102, 481-6.

14. Sakai A, Matsumoto T, Hirai D, Niino T (2000) Newly developed encapsulation-dehydration protocol for plant cryopreservation. CryoLetters 21, 53-62. 